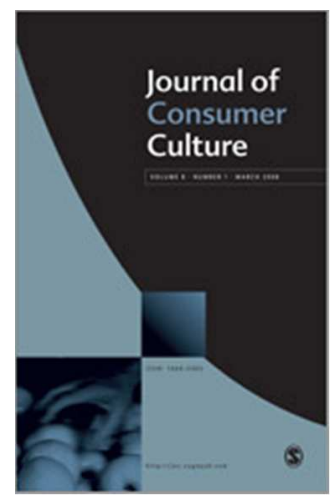

\title{
Disrupting household food consumption through experimental HomeLabs: Outcomes, connections, contexts
}

\begin{tabular}{|c|l|}
\hline Journal: & Journal of Consumer Culture \\
\hline Manuscript ID & JOCC-15-0034.R1 \\
\hline Manuscript Type: & Original Article \\
\hline Keywords: & $\begin{array}{l}\text { Food consumption, Sustainability, Social practice, Food waste, Governance, } \\
\text { Transitions, Ireland }\end{array}$ \\
\hline & $\begin{array}{l}\text { This article explores the implications of conceptualising, designing and } \\
\text { implementing experimental sites seeking to support more sustainable } \\
\text { home-based eating practices; or HomeLabs for brevity. Building on earlier } \\
\text { phases of practice-oriented participatory (POP) backcasting and transition } \\
\text { framework construction, the HomeLabs involved collaboration with public, } \\
\text { private and civil society sectors, as well as with the members of } \\
\text { participating households. These collaborations identified a suite of } \\
\text { supportive socio-technological, informational and governance interventions } \\
\text { that mimicked, as far as possible, the characteristics of promising practices } \\
\text { for sustainable eating developed through backcasting and transition } \\
\text { planning. The implemented interventions enabled householders to } \\
\text { question, dis-assemble and reconfigure their eating practices onto more } \\
\text { sustainable pathways across the integrated practices of food acquisition, } \\
\text { storage, preparation and waste management. This process generated } \\
\text { manifold insights into household eating practices and this paper focuses } \\
\text { specifically on key outcomes of the HomeLabs, and the significance of } \\
\text { social context, social relations and micropolitics of everyday life in shaping } \\
\text { those outcomes. In particular, the HomeLabs findings reinforce calls to } \\
\text { connect, combine and align product, regulatory, informational and } \\
\text { motivational supports across the interdependent practices of eating } \\
\text { (acquisition, storage and preparation and waste recovery) to optimise } \\
\text { transitions towards sustainability. Offering a lens to interrogate } \\
\text { interventions for sustainable food consumption in the home, this paper } \\
\text { provides a novel exercise in operationalising social practice theory. }\end{array}$ \\
\hline Abstractions \\
\hline
\end{tabular}




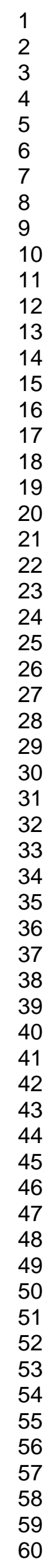

SCHOLARONE $^{\text {th }}$

Manuscripts

http://mc.manuscriptcentral.com/JOCC 
Disrupting household food consumption through experimental HomeLabs: Outcomes, connections, contexts

\begin{abstract}
This article explores the implications of conceptualising, designing and implementing experimental sites seeking to support more sustainable home-based eating practices; or HomeLabs for brevity. Building on earlier phases of practice-oriented participatory (POP) backcasting and transition framework construction, the HomeLabs involved collaboration with public, private and civil society sectors, as well as with the members of participating households. These collaborations identified a suite of supportive socio-technological, informational and governance interventions that mimicked, as far as possible, the characteristics of promising practices for sustainable eating developed through backcasting and transition planning. The implemented interventions enabled householders to question, disassemble and reconfigure their eating practices onto more sustainable pathways across the integrated practices of food acquisition, storage, preparation and waste management. This process generated manifold insights into household eating practices and this paper focuses specifically on key outcomes of the HomeLabs, and the significance of social context, social relations and micropolitics of everyday life in shaping those outcomes. In particular, the HomeLabs findings reinforce calls to connect, combine and align product, regulatory, informational and motivational supports across the interdependent practices of eating (acquisition, storage and preparation and waste recovery) to optimise transitions towards sustainability. Offering a lens to interrogate interventions for sustainable food consumption in the home, this paper provides a novel exercise in operationalising social practice theory.
\end{abstract}




\section{Keywords}

Food consumption, sustainability, social practice, food waste, governance, transitions, Ireland.

\section{Introduction}

As Arnold Tukker and colleagues note, food remains one of the most critical consumption domains from the standpoint of environmental sustainability' (Tukker et al., 2010: 13). A central reason for this stems from the reported environmental impact of societal food production and consumption on greenhouse gas emissions, soil degradation, air and water pollution, water stresses, biodiversity losses and climatic change (UNEP, 2010). From a consumption perspective, vast inequalities in global food security also persist worldwide, with more than 800 million people continuing to suffer from calorie deficiency and a further two billion suffering from one or more micronutrient deficiency (GHI, 2014). At the same time, approximately 3.4 million adults die each year as a result of being overweight or obese (WHO, 2014). Landscapes of food production and consumption are thus far from sustainable in their current configuration. Individually, food consumption contributes $15-35 \%$ of total greenhouse gas emissions of the average European citizen (Hallström et al., 2015). Changing consumer diets globally intensifies this impact, with rising incomes and an expanding middle class increasing meat and dairy consumption worldwide (Larsen, 2012). Further, structural food wastage accounts for $30-50 \%$ (around two billion tonnes) of food produced (IME, 2013). Changes in consumer practice are thus necessary to address these wasteful realities and achieve all four elements of the global food security agenda - availability, stability, utilisation, and access (Schmidhuber and Tubiello, 2007). While supply-side debates dominate policy discussions of feeding growing 
populations under the conditions of climatic change, there is also a pressing need to address demand-side issues if the current unsustainabilities across the food chain are to be addressed (AUTHOR, 2013, 2014).

Recognising that food consumption is shaped by a combination of cultural norms and habits, rules and regulations, modes of provision and infrastructures that together script the ways in which people eat has led to the emergence of a social practice lens for examining the performance and impact of eating (see AUTHOR, 2013, 2014; Sahakian and Wilhite, 2014; Warde, 2013). A social practice approach provides a means through which the socialised performance, but ultimately individual act, of eating can be linked to wider architectures of provisioning and provenance. This is particularly significant in the context of governing processes of change towards more sustainable eating. For it is the case that issues of accessibility and affordability can make attaining a sustainable diet challenging, if not often impossible, for many consumers (Tovey, 2009). Ignoring the complex architecture of factors that influence eating practices, current governing approaches dominated by information provision via on-product labelling or public exhortations to 'eat better', are failing to transform substantially the form of eating landscapes. Experimentation with alternative mechanisms to support practice change are urgently required Building on important insights of both social practice protagonists and the pragmatic responses of transition management practitioners, this paper reflects on the outcomes of implementing such an experimental approach. Extending a practice-oriented participatory (POP) backcasting process that led to the co-production of a transition framework for more sustainable eating (see AUTHOR, et al., 2014a), the construction and outcomes of in-home experiments for more sustainable eating; or HomeLabs for brevity; are documented (AUTHOR et al., 2014; COLLEAGUE and AUTHOR, 2015). In the absence of one agreed definition of sustainable 
eating (see Friedl et al.,2006), the HomeLabs focused on interventions that promoted resource efficient food, including greater usage of regional rather than imported food; organically produced food that limits synthetic chemical use; lower amounts of bottled beverages; and reduced meat diets.

Specifically, this paper aims to deepen current understandings of transitions to more sustainable eating practices by 1) exploring the outcomes of an experimental implementation of a POP backcasting research process; 2) identifying the connections between elements of practices that comprise household eating (acquisition, storage, preparation and food waste management), and 3) detailing the social dynamics and relations evident in the HomeLabs that impacted the nature and scope of practice changes achieved; an understudied arena for sustainability transitions (Hargreaves, 2011; Røpke, 2009).

Before documenting the results of the HomeLabs experiment, the conceptual foundations and design of the HomeLabs approach are outlined. Following this, the paper elaborates on the key findings and impacts of the research, with particular attention paid to householder reactions and responses to the socio-technical interventions implemented. The findings highlight that while uniform interventions were provided to each of the participating households, the reactions to, and impacts of, those interventions were as variegated as the households themselves. The concluding section reflects on the implications of such findings for understanding the multivariate nature of eating practices and for policy makers charged with reorienting the performance of them.

\section{Conceptualising and designing HomeLabs}

As highlighted by Murcott (1992: 14), '[t]he social anthropology of food and eating displays considerable diversity in theoretical approach, research strategy, and 
substantive focus'. Equally, specific aspects of food consumption - be that purchasing, cooking or waste disposal - have tended to be assessed in isolation from each other leading to a fragmented body of knowledge in the field. Recently, however, there has been a visible social practice turn in examining eating which seeks to coalesce such disparate understanding (Warde, 2013), and as such this practice approach provides an appropriate overarching analytical framework for the aims of this paper.

While the literature on social practice theory is large and evolving, in this paper practices are understood to represent both entities in themselves and performances (Reckwitz, 2002). As entities, practices are recognisable, describable and shaped by numerous socio-cultural and material elements, but it is in the 'doing' of a practice that the pattern becomes meaningful, is reproduced and can be modified (Southerton et al., 2012). As a result, practices steer processes of consumption (Warde, 2005) and often do not operate in isolation (Reckwitz, 2002). For example, the practice of eating requires the performance of a number of interconnected practices such that somebody purchases, prepares and cooks the food (Plessz and Gojard, 2014). These practices are often habitual, sometimes semi-conscious in nature, and thus represent obvious targets for behaviour change.

The experimental HomeLabs challenge was to disrupt the norms associated with the intertwined household practices that shape actual moments of food consumption; that is acquisition, storage and preparation and management of food waste. In keeping with established environmental impact assessments of household food choices (Tukker et al., 2010), this included providing households with access to more organic foods and alternative protein sources as well as devices and prompts to help reduce food waste and engage in food waste recovery where appropriate. The relationship between material dimensions of eating practices (e.g. available food options, kitchen appliances and composting facilities) and intangible socio- 
cultural norms (e.g. meal expectations) was of central concern in the HomeLabs research, which explored with household members how they 'understand the meanings of their own performances' (Plessz and Gojard, 2014: 2), both pre and post intervention. Attention to the material and social contexts shaping food practices represents a growing area of research internationally. This includes the role of context in shaping food waste practices (Evans, 2012), food-related anxieties (Jackson et al., 2013) and domestic food provisioning practices (Watson and Meah, 2012). This contextual framing was important for the HomeLabs to establish and understand differentiated commitment to various eating practices (Southerton, 2006) and the level of investment that performers of practices embed within them (Warde, 2005).

Designing HomeLabs

The HomeLabs study identified, implemented and evaluated a suite of interventions which mapped closely onto the short-term measures for sustainable eating co-produced through a practice-oriented participatory (POP) backcasting exercise previously conducted (see COLLEAGUE and AUTHOR (2013)). POP backcasting brought together stakeholders from across the food chain to co-create future visions of sustainable eating, with resultant scenarios depicting a combination of lifestyle, technological and governance innovations. Following evaluation with citizen-consumers, the most promising concepts were outlined in a Transition Framework, setting out interventions required for their achievement (see COLLEAGUE and AUTHOR, 2012). Closing the loop on the backcasting process, the HomeLabs study implemented and evaluated the most promising short-term concepts identified (see Figure 1). 
(INSERT FIGURE 1 HERE)

Drawing inspiration from the broad ethos of emergent living laboratory methodologies (Salter and White, 2013), the HomeLabs combined user-centred and open innovation processes to generate concepts that were then implemented and evaluated in lived environments (AUTHOR et al., 2014). To do this, the research team worked with an array of public, private and civil society actors to identify existing and prototype innovations that reflected those identified through POP backcasting (see Table 1). Working collaboratively with these actors and the householders themselves, technological, regulatory and informational innovations were acquired, tested and evaluated using in-depth, multi-media ethnographic methods within five households located within the greater Dublin region within the Republic of Ireland over a period of five weeks.

(INSERT TABLE 1 HERE)

The HomeLabs adopted a purposive sampling approach based upon recruiting households from the most common household types in Ireland, as identified by the most recent Census (CSO, 2012). Recruitment strategies included group mail outs to office, student, and personal networks, online advertisements on college websites and flyers at garden festivals held in Dublin over the summer of 2014. Within these communications, a number of health, environmental, economic and social benefits associated with partaking in the experiment were outlined to encourage participation, including opportunities to plan and create healthier meals, decrease carbon food footprints, save money and learn new food skills. The final selection of households was not intended to form a statistically representative sample, 
though in keeping with ethnographic studies of household food waste conducted by Evans (2012), the final selection displayed heterogeneity regarding household structure (from single person to family and non-familial households), age of participants (from 18 months to 63 years) and location (rural to urban). None of the households saw themselves as early adopters of strong sustainability practices. Ultimately however, household participation in the Homelabs was inevitably shaped by practical constraints relating to householder availability and accessibility by the research team. The key characteristics of the five final households selected for full experimentation are detailed in Table 2.

(INSERT TABLE 2 HERE)

HomeLabs interventions and impacts

Working with the stakeholders outlined in Table 1, the research team identified a suite of prototype, near-to-market or niche tools, governance and educational interventions that aimed to collectively script and support opportunities for more sustainable eating in the home. Bundles of interventions were phased into households over the study period (see Figure 2). Following initial data collection regarding pre-existing practices in week 1, week 2 focused on sustainable food acquisition and involved experimentation with food growing kits, organic food boxes and sustainable protein sources. A carbon footprint graph meanwhile aimed to connect consumers with the impacts of their food acquisition practices and was supported by informational supports for more sustainable supermarket shopping and seasonal food charts. Week 3 promoted more sustainable 
food storage and preparation techniques and included the introduction of fridge triage boxes to assist householders with more accurate food circulation, identifying the food due to be eaten next or close to its use by date as laid out in accompanying food storage and safety guidelines. Portion control tools meanwhile aimed to encourage more sustainable cooking practices, while a visit from a chef sought to inspire meal planning techniques and debunk the myth of food convenience with tailored cooking tips. Finally, week 4 focused householders on further reducing their food waste and engaging in appropriate food waste recovery. Targeted product interventions included kitchen caddies to assist with food waste segregation and electronic composters as an alternative to traditional composting heaps. This was supported by information on the economic costs of food waste and home composting. In week 5, participants continued with their preferred practices and reflected on the overall impact of participating in the HomeLabs.

The impacts of the study were evaluated using data from households gathered through a process of mixed method, ethnographic techniques. The foundational core of this data collection comprised of a visit to each household once a week to explore the participants experiences of that week's interventions, collect data on the impact of the interventions and brief participants on the interventions to be implemented the following week. Semi-structured interviews conducted during these visits enabled some commonality of data gathering, but also allowed participants to speak freely with the researcher and to raise issues relevant to their experience (Hoggart et al., 2002). To assist with analysis, all interviews were digitally recorded, transcribed and analysed using the qualitative software package NVivo 10. In addition, a group Facebook page supported interaction with the research team beyond the household visits and permitted householders to share photos, thoughts and reactions to their HomeLabs experience. A food 
waste audit, as similarly utilised by Langley et al. (2010), was conducted in week 1 and 5 to assess the impact of HomeLabs participation on the generation and composition of food waste. Food waste was collected by householders for three days in advance of their next researcher visit, with participants asked to make a record of the type of food wasted and the reason for wasting it. The gathered food waste was then weighed by the researcher ${ }^{1}$.

(INSERT FIGURE 2 HERE)

\section{Experimental HomeLabs: Outcomes, connections and context}

During the HomeLabs, changes in eating practices were noted across the participating households highlighting the ability of the interventions to challenge, disassemble and reconfigure eating practices onto more sustainable pathways. For example, over the course of the experimental period, participant households reduced their overall food waste generation by $28 \%$ (including reductions of up to $5.25 \mathrm{~kg}$ in Household $\mathrm{M}$ ), with additional shifts towards more sustainable purchasing, storage, preparation and waste recovery practices also identified.This paper focuses on the key outcomes of the HomeLabs process as reported by the householders, with particular attention paid to the impact of the interventions in challenging, disassembling and reconfiguring eating practices (Hargreaves, 2011). In doing so, the paper highlights the process and outcomes of testing social practice approaches in lived settings and the variegated reactions that this can generate in response to differentiated social contexts.

\section{Key HomeLab outcomes}

Within the food acquisition phase, participants reported an increased awareness of the environmental impact of their purchasing choices, with all households discussing their attempts 
to acquire foods with a lower carbon footprint as well as more organic produce when purchasing foods outside of the provided HomeLabs products. It was the combination of material and informational interventions that was particularly influential here, with a carbon graph and the provision of new food items providing the initial impetus to try new food provenances. The HomeLabs strategy then aligns directly with the social practice approach proposed by Shove (2003) and Warde (2005) that recognises the complex architecture of material and social constructs influencing the performance of practices. Here, the physical provision of foodstuffs altered the material constructs available to householders while the carbon graph simultaneously provided a form of regulatory frame and learning opportunity for participants to engage in more sustainable eating practices. For instance, after experimenting with the organic fruit and vegetable box, both Household FA and Household FY actively commenced new organic purchasing practices in their wider food acquisition practices, swapping out several conventional items for their organic alternatives (including spaghetti, tinned goods and fruit). Resonating with Evans $(2012, \mathrm{p52})$ identification of the refrigerator as 'an active participant in the process of devaluation and decay' and Metcalfe et al.'s (2012) emphasis on the food waste bin as a type of local waste infrastructure, this result highlights the ability of material constructs to disrupt established practices.

Nonetheless, while financial constraints undoubtedly also play a role in determining food acquisition choices (Tovey, 2009), participants sought to modify their purchases (outside of the provided HomeLabs products) to incorporate more sustainable options where this was seen as feasible and positive for their overall eating experiences.

'Every week since l've started l've bought and replaced a few different things with organic ... [it's] making me think, yeah that I need to look at what's going into the food and definitely the taste is always better' (Joanne, Household FY) 
'We feel much better eating organic food. Feel it is better for us and better for the earth' (Catherine, Household FA)

More efficient techniques in relation to food storage and preparation were implemented across households as a result of participating in the HomeLabs, with households discussing their enhanced ability to keep food fresher for longer, preventing avoidable food waste. Such findings connect with the work of Quested et al. (2011) and others who report a need for consumer engagement in more efficient storage techniques to reduce preventable food waste. In the HomeLabs, a guide to smarter food storage proved particularly popular with the more experienced cooks across Household FA, Household FY and Household S who commented on mistakes that they had previously been making in their established food storage practices:

I certainly got loads of ideas of food storage [despite]...cooking for 50 odd years. Things like not storing the bananas in [the fruitbowl] because they are better kept away from the other [fruit]' (Catherine, Household FA)

I've put all my fruit now that I wouldn't normally into the fridge...I used to just keep it out but then it did go...off very fast' (Joanne, Household FY)

Moreover, the provision of non-meat proteins during week 4 led to future commitments to consume more vegetarian meals across household types as part of an effort to reduce carbon intensity in diets, further demonstrating the disruptive capabilities of new material constructs (Evans, 2012; Metcalfe et al., 2012). These vegetarian protein options were provided alongside appropriate recipe ideas prompting new dialogues and strategies within households to explore reduced meat consumption. This result is particularly notable given the limited efficacy of meatfree information campaigns to date (Laestadius et al., 2014). The reinforcement approach of the 
HomeLabs is key here, with successful adoption of more vegetarian practices stemming from the simultaneous provision of affordable and appropriate products (vegetarian proteins were provided free to households for one week) and materials highlighting the carbon impacts of food (carbon graph), alongside provocative ideas about how to alter eating practices (vegetarian recipe ideas). Here, 'material and ideological contexts [combine to]...give the work of feeding its distinctive shape' (DeVault, 1991, p95), moving beyond traditional communication campaigns to organise eating practices in the home. While no participants expressed a desire to become a vegetarian - claiming a paucity of taste and satiety in a purely vegetarian diet - commitments to eating more vegetarian options as part of weekly routines were commonly articulated.

'Previously I would just eat a lot of mince. Now I would be more than happy just to have veggies or...if you eat half mince half beans... they are healthy. They help bulk up your dinner, they give you protein and stuff. But they are not bad for you or expensive' (Alan, Household C)

Finally, changes in food waste prevention, segregation and recovery practices were also evident across participant households. According to Evans (2012), the transition of food into waste arises as a direct consequence of domestic practices and, in particular, the way in which these practices are materially and socially organised. Representing the 'fall out of the organization of everyday life' (Watson and Meah, 2012: 116), attention to food waste mobilities (AUTHOR, 2012) is thus crucial to further understand how food is 'moved along' (Gregson et al., 2007) within the home. Indeed, aside from the noted overall reduction in food waste generation by $28 \%$ during the HomeLabs, two households that never segregated or composted food waste previously (Household C and Household M) 
commenced these practices as a result of participating in the HomeLabs. Altering householder views on the value of, and further uses for, food waste (Evans et al., 2013), the food waste boxes provided for segregating food waste and the electronic composter interventions sparked a radical transformation in these practices for these participants. Such new segregation practices even had positive spill-over effects in Household $M$ with a belief that they began recycling all of their waste more efficiently as a result of commencing practices of food waste segregation. By comparison, in Household S and Household FY who previously segregated but never composted food waste, the food waste boxes had limited impact, with these householders preferring to continue using their existing non-compostable food waste caddies. This finding reinforces the observation of Reckwitz (2002) who emphasises the strength of previously established practices reproduced over time. These participants felt that they were already performing appropriate waste segregation practices. Nonetheless, the electronic composter sparked curiosity and intrigue in these households and was seen as an improvement on traditional outdoor composting methods from the perspective of convenience. Finally, for Household FA who segregated and composted food waste before the HomeLabs, the food waste recovery interventions did not spark the same degree or intensity of practice change.

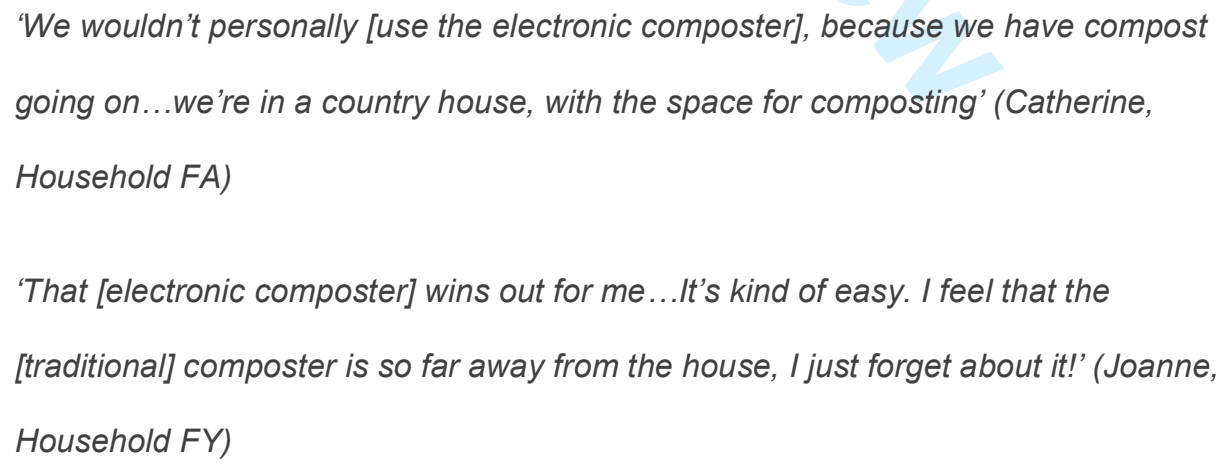


Such differentiated impacts highlight the tendency for completely novel interventions (as perceived by the householders) to initiate more dramatic disassembly and reconfiguration of practices compared to minor tweaks to existing routine. More broadly, this finding reflects the 'internally differentiated and dynamic' nature of consumption practices and the varying levels of practice commitment that can ensue (Warde, 2005: 131). While all practices 'contain the seeds of constant change' (Warde, 2005: 141) and HomeLab participants indeed experimented with new food waste recovery practices, those with previously established segregation and composting routines decided to return to these familiar, established performances while others expressed commitment to their new ‘improved' regimes.

Most notably, the outcomes of the HomeLabs, both in terms of participant reactions and evidenced impacts, highlight the success of integrated or 'connected' bundles of product, regulatory and informational interventions for supporting more sustainable eating practices. This theme of connection is fleshed out in the following section.

\section{Connections}

Combining information about the impact of current consumption practices - achieved through the food waste audit - with practical tools and tips designed to help reduce that impact ultimately contributed to the degree of practice-changes the HomeLabs generated. Indeed participants noted how many of the interventions would have little efficacy in isolation.

'The information pack to be honest won't make sense unless you see the stuff and get it actually working. Because, realistically...you don't really read things in depth' (Maeve, Household C) 
A ranking activity, conducted in the last week of the HomeLabs to explore which interventions were most significant for the participants, identified to the importance of face-to-face interaction with the research team to support the questioning and reconfiguring eating practices.. This interaction enabled tailored re-scripting of practice performances for all participants.

\author{
'To be honest I don't think we would have gotten as much of an impact or \\ understanding if we hadn't... [had the researcher's] interaction...I really don't think I \\ would've understood it as much if I hadn't been [visited]. I think I changed my \\ behaviour because it was you' (Maeve, Household C) \\ 'You didn't just give the stuff, you explained what to do with it. And l'd sit down in my \\ own time and l'd read it properly, and observe and take it in' (Marian, Household S)
}

Such findings are in contrast with an ethnographic study conducted by Evans (2012) whereby the presence of a researcher in the home discussing food waste failed to significantly alter routines for some families (in other words, they did not waste less food throughout the experiment duration). The difference in impact perhaps lies in the fact that Evans (2012) did not implement any interventions or supports with his households to induce practice changes compared to the fully supported HomeLabs. In the HomeLabs experiment, the researcher effectively and explicitly acted as a change agent (Pettigrew, 2003), navigating the complex arena of food consumption options and shouldering the burden of identifying, procuring and providing products, devices and informational materials to participants. Further, the researcher acted as a sounding board, a source of knowledge and inspiration, and an important external driver for participants to persist with reconfigured practices even when this required additional learning and effort in the transitional phase. This generated important social interaction and built relations of trust (Cohn, 2015). Such benefits 
should not be underestimated, but therein lies a considerable challenge for those driving sustainable eating paradigms. How can the difficult transitional phase of disassembly and reconfiguration be achieved without the resource intensity, cost and time of deploying a team of change agents into people's houses? Indeed, how many people would wish to open their doors, kitchens and bins to external actors for the period of time needed to disassemble and reassemble practices? These issues have long been recognised in literature on environmental citizenship in particular (Hobson, 2003; Hargreaves, 2011), but are thrown into sharp relief through the HomeLabs process. Nonetheless, while the researcher was the catalyst in the HomeLabs assembling opportunities for the repeated performance of novel eating practices and opening up spaces for new norms to develop within households, the tools, information and rules were also pivotal in creating an architecture for more sustainable eating. With the withdrawal of the researcher at the end of the five week period, it is these material and informational actants (Latour, 2004) which remain as the enduring supports for practice configurations. Finally, the experimental HomeLabs approach highlighted the need to address and connect multiple interdependent practices of eating (acquisition, storage, preparation and waste recovery) for more holistic transitions to sustainable food consumption. Other studies, policies and campaigns have tended to isolate these connected practices, attempting to encourage practice change in one arena to the neglect of its interconnected elements. For example, multiple studies have focused solely on the drivers behind organic food purchasing (Onyango et al., 2007) or consumer interactions with farmer's markets (Hunt, 2007). Such studies often fail to acknowledge the complex nature of food consumption that leads consumers to conduct multiple food acquisition practices at different times and according to different needs, wants, preferences, life stages and financial constraints. Regarding food storage and preparation, a number of studies have also tended to exclusively focus attention on kitchen 
practices, be it in terms of food safety (Wills et al., 2015) or cooking skills (Lyon et al., 2011).

Others emphasise the pressing need to reduce meat consumption (Garnett, 2011) but in isolation of the impact of other food consumption choices, for example, whether the plant-based substitutes for meat are obtained from a local source or are organic in nature.

Elsewhere, some studies combine elements of the practices connected in the HomeLabs, though none as extensively as in this study. For example, Watson and Meah (2012) explore the trade-offs between food waste and safety agendas connecting kitchen management and wasting practices in the home, while Meah and Watson (2013) examine consumer ethics related to purchasing and provisioning practices. Similarly, Evans (2012) connects food purchasing to household storage and waste generation, albeit with no attention to the organic, local or low carbon qualities of the purchased food. Capellini and Parsons (2012: 121) likewise highlight the need to look beyond the mere consumption of meals when exploring social relations in the home, to instead examine the 'series of practices surrounding the business of feeding the family'. This includes meal planning, food shopping, cooking and serving meals as well as the often neglected phases of waste disposal or use of leftovers. Again, however, Cappellini and Parsons (2012) pay no attention to the environmental credentials of the food acquired in the first place, nor the practices of composting performed thereafter. Indeed, the way in which the themed weeks of the HomeLabs (acquisition, storage and preparation, food waste recovery) came together proved popular with participating households, with members of Household $\mathrm{C}$ and Household $\mathrm{M}$ specifically highlighting the benefits of the phased approach.

'At the end, that you can kind of see a cycle of it so it all makes sense' (Caroline, Household M) 
'It was like you weren't being overloaded...I think definitely having an inch to inch to inch [phasing of interventions]. And then I think stuff starts making sense' (Maeve, Household C)

Connecting elements of eating is thus necessary to achieve an overarching picture of sustainable eating; one that encompasses the acquisition of seasonal, low carbon and organic food, its efficient storage and management in the home for reduced food waste, and final waste recovery appropriate to remaining unavoidable food waste. Linking up this range of subpractices was a defining feature of the HomeLabs and a quest for more holistic transitions to sustainable eating (as opposed to, for example, just reducing food waste). However, while the connectivity of the entire eating system, as well as the need to connect interventions targeting skills, rules, tools and understandings, was identified by all participants as an important component of initiating practice change, it also became clear over the duration of the HomeLabs that the uniform interventions stimulated changes that varied in form and intensity across, and even within, households. Given the entanglement of food consumption practices 'in webs of social reproductions and change' (Halkier and Jensen, 2011: 102), interventions were experienced differently as they entered novel situations with specific social relations and dynamics created by diverse household structures, lifestages and familial contexts. This final key insight from the experimental HomeLabs is explored below.

\section{Contexts}

Assessing areas of commonality and divergence between household reactions to identical HomeLabs interventions reveals the importance of social relations and the (micro)politics of everyday life on resultant practice changes; a neglected area according to practice scholars (Hargreaves, 2011; Røpke, 2009). As Hargreaves (2011:93) notes, a close relationship exists 
'between practices and the power and social relations that they support and uphold'. Such relationships were evident in the HomeLabs with some sustainable eating practice interventions (such as the meal planning techniques and the fridge triage box) more easily adopted in families in which one member assumed responsibility for more sustainable food acquisition, storage and preparation on behalf of the entire household.

'I know I mainly do the shopping...I don't think I'll buy as much as I used to because that's one thing that I've learned. (Joanne, Household FY)

'Definitely our storage of food has changed. I've even noticed that. And that's with Mam doing most of the storage' (Eilise, Household FA)

This compares to difficulties experienced in other households such as the three members of Household M, a group of friends co-habiting, who shop, cook and dispose of food independently of one another. The absence of a co-ordinating agent for change in these non-familial households is key here, given the reported role played by such champions in instigating proenvironmental practices in other contexts, including businesses (Schaefer, 2004) and universities (Ferrer-Balas et al., 2008). As the HomeLabs revealed, collective eating facilitates collective food acquisition and shopping routines, therefore avoiding food product duplication and the potential for food waste. Providing supports to encourage the coming together of households around specific meal events thus proved difficult to enact in non-familial settings.

I'd say even one [collective] meal a week might be a bit ambitious... Maybe if you had mixed professionals who were teachers and all finished at the same time, it would be different' (Caroline, Household M) 
Furthermore, where certain cooking skills were already in place (even if they had not been utilised extensively before the HomeLabs) there tended to be greater willingness to implement new sustainable shopping and cooking habits; whereas a paucity of skills provided a greater barrier to change. This resonates with the work of Evans (2012) who highlights the significant role played by individual cooking ability, confidence and competence (matters influenced by background and biography) in the generation of food waste in the home (directly influencing cooking styles and ability to construct meals out of leftovers). Such differing baseline skills and interest in cooking were apparent in Household $\mathrm{M}$, with one participant in particular lacking confidence to create meals using unfamiliar but more sustainable protein options, despite the impact of the chef visits and recipe card supports.

'I'd say if you knew more veg recipes off hand then it wouldn't have been such an effort...I wouldn't know what to have like for lunch' (Caroline, Household M)

By comparison, the two familial households (Household FA and FY) both possessed one member (who tended to be both the predominant food shopper and cook) who was willing to take responsibility to establish more sustainable eating routines on behalf of the entire family. Acting as key agents for change (Ferrer-Balas et al., 2008; Schaefer, 2004), it was these participants who assumed principal responsibility for implementing the HomeLabs interventions. For example, the mother in Household FA began purchasing more organic and low carbon foods as part of the weekly shopping routine and also organised the family refrigerator around the specifications and tools provided by the HomeLabs team. Such practices reduced the need for other household members (principally the champion's partner and children) to exert much effort in, or attention to, transforming their eating practices; they were passive rather than proactive in the process. Yet, in some cases the assumption of roles by household members was 
also felt to constrain active uptake of new practices by others. The adult daughter living at home in Household FA, for example, expressed difficulties in having access to the kitchen to prepare her own meals and felt dependent on her mother's shopping and cooking practices. Such maternal dominance (also evidenced in Household FY) is not unique, but maps easily onto established traditions, cultural norms and social relations literature related to the division of labour in the home (DeVault, 1991). The persistence of such traditional roles means however, that the learning around reconfigured practices tended to reside primarily with certain actors within the HomeLabs. This creates uncertainty about the wider learning of practice configuration of other participants, or when the structures of their dwelling alter (for example, beyond the home or following key lifecourse transitions upon moving out of the familial home (Burningham et al., 2014)).

Household C, by contrast, were a time-pressed couple leading busy lifestyles with significant work commitments and multiple hobbies. Both participants from this household felt that they had insufficient time to implement all of the practice changes being prompted by the HomeLabs interventions. This aligns with Evans (2012) who highlights the need to acknowledge the socio-temporal context of food practices, with much 'proper' food preparation imposing significant and, sometimes unachievable, demands on time. Furthermore, Evans (2012, p53) notes how the passage of food into waste often occurs as a result of householders 'negotiating the contingencies of everyday life' when enacting their ordinary domestic practices. Similarly, in the HomeLabs, the female member of the Household $C$ felt obliged to take the lead in implementing the interventions provided, but was thereafter frustrated by a lack of capacity to make significant changes to eating practices. 
'You do need time to be prepared.... chatting [with the visiting chef] about preparing meals and doing soups and stuff and I was like 'I don't have time' [wails]...I'm doing whatever is handiest and that I can get a lot of dinners out of' (Maeve, Household C)

Assessing emergent and differentiated patterns of practice change in the HomeLabs, it is obvious that differences exist in consumer ability and willingness to achieve sustainable practice changes both between, and within, households. As carriers of social practices individuals move through life becoming recruited to the various tasks that everyday social practices require. The ability and desire to develop sustainable patterns of consumption are thus deeply embedded within a wider range of everyday practices that often have a long trajectory, are unconsciously performed and are socially embedded (Reckwitz, 2002; Warde, 2005; Halkier and Jensen, 2011). As such, the HomeLabs interventions induced diverse reactions amongst participants with variegated social relations, histories and lifestages across households representing a plausible explanation for this uneven impact. In particular, the role of living context, household dynamics, time pressures, social positioning and the presence of active change agents within the household were particularly influential. Such findings mean that homogenous sustainable eating policies, messages or tools will not create uniform impacts and changes across society, re-emphasising the need to focus on practices, as opposed to the individual, when attempting to create sustainable behaviour change.

\section{Conclusion}

Paying attention to both the 'internal dynamics and the external conditions' of practice development (Warde, 2005: 148), the findings of the HomeLabs highlight the importance of understanding the impact of context, social relations, motivating forces and micropolitics in any 
endeavour to shift food consumption onto more sustainable trajectories. The nuances of everyday life create significant challenges for developing appropriate supports for households to adopt sustainable eating practices. The HomeLabs sought to navigate this challenging environment with its phased introduction, and combination, of motivational, informational, regulatory and product supports.

Focusing on a different eating practice each week further assisted the process of practice change and prevented participants from feeling overwhelmed by interventions. The need for such an individualised and supported approach however raises questions in terms of rolling out mechanisms supporting sustainability transformations within the home (AUTHOR and COLLEAGUE, 2015). It is not feasible, neither economically or temporally, to provide such concentrated attention to individual households nationwide. Nonetheless, the HomeLabs provide important insights for community-based movements (such as transition towns), product developers (both start-up entrepreneurs and multi-national companies), and government supported initiatives (such as the Green Homes initiative in Ireland), which will play a key role in delivering societal transformations in the food arena. Specifically, the HomeLabs results indicate that aligning regulatory frames, informational supports, devices, motivational prompts and products in flexible ways is more likely to lead to reconfigured practices than interventions that focus on one element alone. However, bringing these disparate communities of practice together given their different mandates and agendas is no simple task.

Applying a practice theory approach both in the implementation and analysis of the HomeLabs allowed for 'the social organisation of consumption' (Halkier and Jansen, 2011: 106) to be acknowledged and assessed in the transition to more sustainable eating practices in the home. Results demonstrate that even with uniform material contexts (applied interventions), differentiated social relations and dynamics in households result 
in variegated impact and recruitment to sustainable eating practices. Only through reflecting on the social, cultural, infrastructural, contextual and individual reasons for unsustainable eating routines (as through a practice approach), and the micropolitics at play in altering everyday decisions, can practices ultimately be disassembled and reassembled onto more sustainable pathways. Such an approach is not merely a theoretical or conceptual frame however, and can be used as a springboard for engaging with citizen-consumers in their own homes. The results documented in this paper already provide important insights in terms of what it means to operationalise the outcomes of participatory backcasting and transition management techniques through a social practice approach in lived settings.

Certainly, further longitudinal investigation is required to reveal the extent to which the temporally delineated HomeLabs might contribute to enduring and transformative change to eating practices. More generally, the outcomes of the HomeLabs experiments reiterate the challenges inherent in scaling-up and out such practice-oriented interventions for more sustainable eating and flag the importance of building a comparable evidence base of such experiments internationally.

Notes:

1. Follow-up assessments will be conducted by the research team with householders six and twelve months after the experiment to assess the longevity of any practice changes achieved. 
References (EXCLUDING AUTHOR'S OWN FOR ANONYMITY)

Burningham KA, Venn S, Gatersleben B, Christie I, Jackson T (2014) New Motherhood: a moment of change in everyday shopping practices?. Young Consumers 15 (3):211-226.

Cappellini B and Parsons E (2012) Practising thrift at dinnertime: mealtime leftovers, sacrifice and family membership. The Sociological Review 60(S2):121-134.

Cohn S (2015) 'Trust my doctor, trust my pancreas': trust as an emergent quality of social practice. Philosophy, Ethics, and Humanities in Medicine 10(9):1-9.

CSO (2012) Profile 5: Households and Families, Central Statistics Office. Available: http://www.cso.ie/en/media/csoie/census/documents/census2011profile5/Profile,5,Hous eholds, and,Families, full,doc,sig,amended.pdf (accessed: 18 January 2015).

DeVault M (1991) Feeding the Family: The Social Organization of Caring as Gendered Work. London: University of Chicago Press.

Evans D (2012) Beyond the Throwaway Society: Ordinary Domestic Practice and a Sociological Approach to Household Food Waste. Sociology 46(1):41-56.

Evans D, Campbell H and Murcott A (2013) Waste matters: new perspectives of food and society. UK: Wiley \& Sons.

Ferrer-Balas D, Adachi J, Banas S et al. (2008) An international comparative analysis of sustainability transformation across seven universities. International Journal of Sustainability in Higher Education 9(3):295-316.

Friedl B, Omann I and Pack A (2006) Socio-economic drivers of (non-)sustainable food consumption: An analysis for Austria. In Charter M and Tukker A (eds) Proceedings to 
the Launch Conference of the Sustainable Consumption Research Exchange (SCORE!) Network. Part IV:45-64.

Garnett T (2011) Where are the best opportunities for reducing greenhouse gas emissions in the food system (including the food chain)?. Food Policy 36(1):S23-S32.

GHI (2014) Global Hunger Index: The Challenge of Hidden Hunger. International Food Policy Research Institute Available: http://www.ifpri.org/publication/2014-global-hunger-index (accessed 18 January 2015).

Gregson N, Metcalfe A and Crewe $L$ (2007) Moving things along: the conduits and practices of divestment in consumption. Transactions of the Institute of British Geographers 32(2):187-200.

Halkier B and Jensen I (2011) Methodological challenges in using practice theory in consumption research. Examples from a study on handling nutritional contestations of food consumption. Journal of Consumer Culture 11(1):101-123.

Hallström E, Carlsson-Kanyama A and Börjesson P (2015) Environmental impact of dietary change: a systematic review. Journal of Cleaner Production 91(15):1-11.

Hargreaves T (2011) Practice-ing behaviour change: Applying social practice theory to proenvironmental behaviour change. Journal of Consumer Culture 11(1): 79-99.

Hobson K (2003) Thinking habits into action: the role of knowledge and process in questioning household consumption practices. Local Environment 8(1):95-112.

Hoggart K, Lees L and Davies A (2002) Researching Human Geography. London: Arnold.

Hunt AR (2007) Consumer interactions and influences on farmers' market vendors. Renewable Agriculture and Food Systems 22(1):54-66. 
IME (2013) Global Food: Waste Not, Want Not, Institution of Mechanical Engineers. Available: http://www.imeche.org/knowledge/themes/environment/global-food (accessed 14 March 2015).

Jackson P, Watson M and Piper N (2013) Locating anxiety in the social: The cultural mediation of food fears. European Journal of Cultural Studies 16(1):124-142.

Laestadius LI, Neff RA, Barry CL and Frattaroli S (2014) No Meat, Less Meat, or Better Meat: Understanding NGO Messaging Choices Intended to Alter Meat Consumption in Light of Climate Change. Environmental Communication DOI: 10.1080/17524032. 2014.981561.

Langley J, Yoxall A, Heppell G, Rodriguez EM, Bradbury S, Lewis R, Luxmoore J, Hodzic A and Rowson J (2010) Food for thought? A UK pilot study testing a methodology for compositional domestic food waste analysis. Waste Management \& Research 28(3):220-227.

Larsen J (2012) Meat Consumption in China Now Double That in the United States. Available: http://www.earth-policy.org/plan b updates/2012/update102 (accessed 14 March 2015).

Latour B (2004) The Politics of Nature: How to bring the sciences into democracy. Cambridge MA: Harvard University Press (translated by Porter C).

Lyon P, Sydner YM, Fjellström C, Janhonen-Abruquah H, Schröder M and Colquhoun A (2011) Continuity in the kitchen: how younger and older women compare in their food practices and use of cooking skills. International Journal of Consumer Studies 35(5):529-537. 
Meah A and Watson M (2013) Cooking up Consumer Anxieties about "Provenance" and “Ethics”. Food, Culture \& Society 16(3):495-512.

Metcalfe A, Riley M, Barr S, Tudor T, Robinson G and Guilbert S (2012) Food waste bins: bridging infrastructures and practices. The Sociological Review 60(S2):135-155.

Murcott A (1992) Anthropology (Sociology?) and Food: Diversity in Scope, Approach and Evidence. British Food Journal 94(7):14-19.

Onyango BM, Hallman WK and Bellows (2007) Purchasing organic food in US food systems: A study of attitudes and practice. British Food Journal 109(5):399-411.

Pettigrew PJ (2003) Power, conflicts, and resolutions: A change agent's perspective on conducting action research within a multiorganizational partnership. Systemic Practice and Action Research 16(6):375-391.

Plessz M and Gojard S (2014) Fresh is Best? Social Position, Cooking, and Vegetable Consumption in France. Sociology 49:172-190.

Quested TE, Parry AD, Easteal S and Swannell R (2011) Food and drink waste from households in the UK. Nutrition Bulletin 36(4):460-467.

Reckwitz A (2002) Toward a theory of social practices: a development in culturalist theorizing. European Journal of Social Theory 5(2):243-263.

Røpke I (2009) Theories of practice - New inspiration for ecological economic studies on consumption. Ecological Economics 68(10):2490-2497.

Sahakian M and Wilhite H (2014) Making practice theory practicable: towards more sustainable forms of consumption. Journal of Consumer Culture 14(1):25-44. 
Salter R and White S (2013) Collaborative research in the real world: Review of Living Laboratories. Sydney, CRC For Low Carbon Living Ltd.

Schaefer A (2004) Corporate sustainability - integrating environmental and social concerns?. Corporate Social Responsibility and Environmental Management 11(4):179-187.

Schmidhuber J and Tubiello FN (2007) Global food security under climate change. PNAS 104(50): 19703-19708.

\section{Shove E (2003) Comfort, Cleanliness and Convenience: The social organisation of} normality. New York: Berg publishers.

Southerton C (2006) Analysing the Temporal Organization of Daily Life: Social Constraints, Practices and their Allocation. Sociology 40(3):435-454.

Southerton D, Díaz-Méndez C and Warde A (2012) Behavioural Change and the Temporal Ordering of Eating Practices: A UK-Spain Comparison. International Journal of Sociology of Agriculture and Food 19(1):19-36.

Tovey H (2009) 'Local Food' as a Contested Concept: Networks, Knowledges and Power in Food-based Strategies for Rural Development. International Journal of Sociology of Agriculture and Food 16(2):21-35.

Tukker A, Cohen MJ, Hubacek K and Mont O (2010) The Impacts of Household Consumption and Options for Change. Journal of Industrial Ecology 14(1):13-30.

UNEP (2010) Assessing the Environmental Impacts of Consumption and Production: Priority Products and Materials. Available: http://www.greeningtheblue.org/sites/default/files/Assessing\% 

(accessed 14 March 2015).

Warde A (2005) Consumption and Theories of Practice. Journal of Consumer Culture 5(2):131153.

Warde A (2013) What sort of a practice is eating?. In Shove E and Spurling N (eds) Sustainable Practices: social theory and climate change. London: Routledge, pp17-30.

Watson M and Meah A (2012) Food, waste and safety: negotiating conflicting social anxieties into the practices of domestic provisioning. The Sociological Review 60(S2):102-120.

WHO (2014) Obesity and Overweight. Available: http://www.who.int/mediacentre/factsheets Ifs311/en/ (accessed 14 March 2015).

Wills WJ, Meah A, Dickinson AM and Short F (2015) ‘ don’t think I ever had food poisoning'. A practice-based approach to understanding foodborne disease that originates in the home. Appetite 85:118-125. 
ALL FIGURES AVAILABLE IN COLOUR ON REQUEST

\begin{tabular}{|c|c|}
\hline & Short $(2012-2020)$ \\
\hline \multirow{7}{*}{ 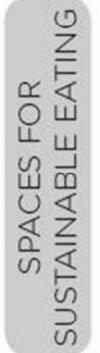 } & (R) Identify and map spaces for growing, cooking and eating \\
\hline & (B) Research is conducted about flexible work models \\
\hline & (E) Support community agriculture and local food markets \\
\hline & (E) Local and national 'champions' promote sustainable food \\
\hline & (E) Networking of sustainable food and food waste groups \\
\hline & (P) Regulations restrict advertisements about unhealthy food \\
\hline & (R) R\&D into the benefits and challenges of vertical farming \\
\hline \multirow{7}{*}{ 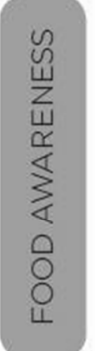 } & (R) Standards for simple labelling system for sustainable food \\
\hline & (R) R\&D on life cycle impacts and environmental footprints of food \\
\hline & (E) Social marketing to generate pride in health and wellbeing \\
\hline & (E) 'Food Dudes' healthy eating programme is expanded \\
\hline & (E) Sustainable food education integrated in 'green schools' \\
\hline & (E) Cooking courses provided in supermarkets by celebrity chef \\
\hline & (E) Raise awareness of health \& environmental impacts of food \\
\hline \multirow{7}{*}{ 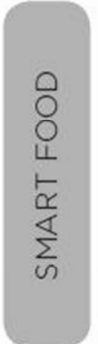 } & (A) R\&D: development of intelligent devices in kitchens \\
\hline & (R) R\&D: closed loop systems \& energy recovery from waste \\
\hline & (E) Familial learning of traditional food skills is encouraged \\
\hline & (P) Guidance on policy around food safety, risk and liability \\
\hline & (E) Opportunities to co-create food innovations are provided \\
\hline & (R) R\&D: personalised nutritional needs linked to technologies \\
\hline & (E) Debunk the 'myth of convenience' in relation to food \\
\hline LEGEND & (E) Education \& Community \\
\hline
\end{tabular}

Figure 1. Short term interventions outlined in the Transition Framework for more sustainable food consumption (Pape and Davies, 2012). 


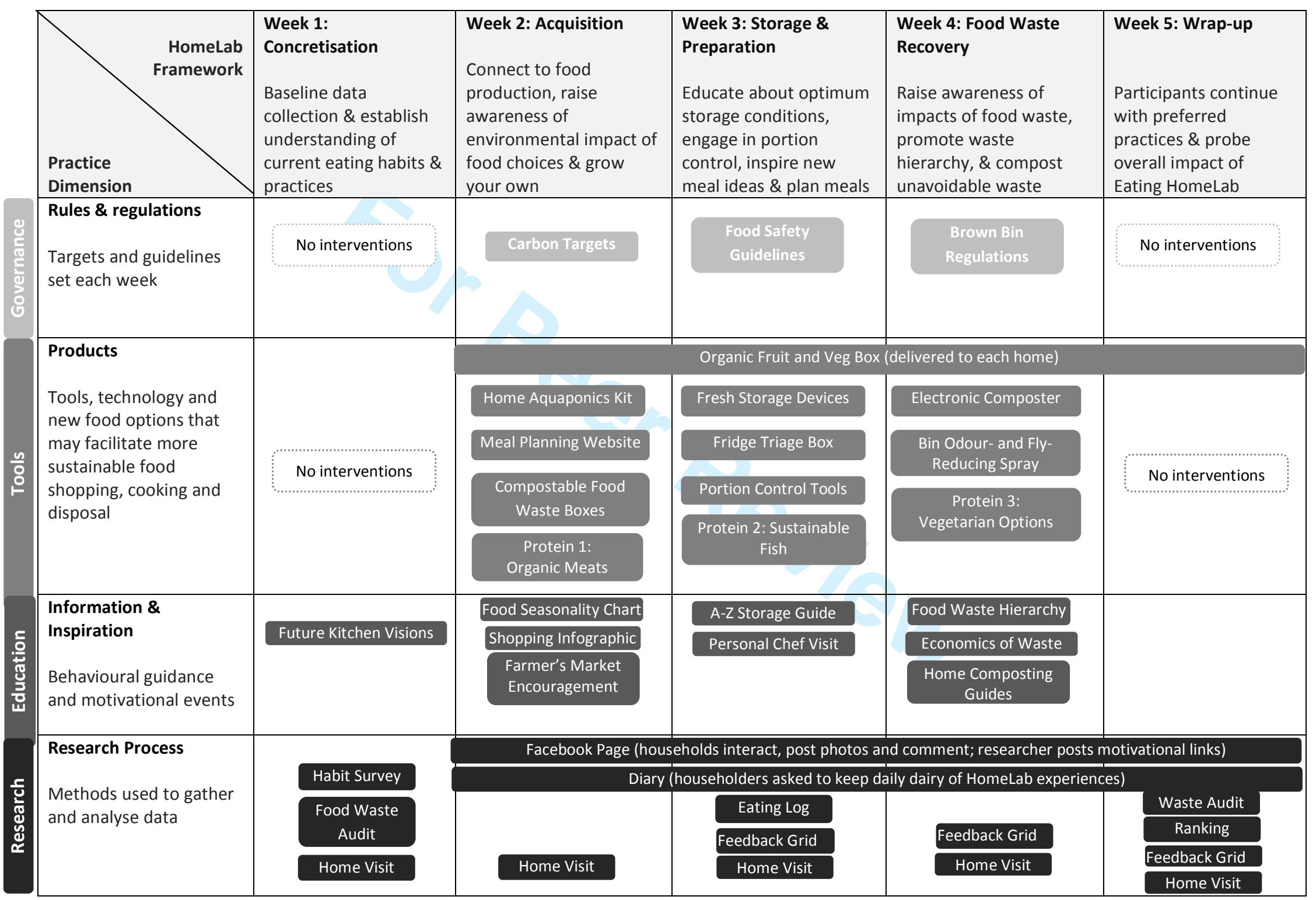

Figure 2. The Eating HomeLab process 
Table 1. Stakeholders engaged in the final delivery of the Eating HomeLabs.

\begin{tabular}{|ll|}
\hline Sector & Stakeholder, area of expertise and location \\
\hline Private & $\begin{array}{l}\text { Food Acquisition } \\
1 \text { Grow-It-Yourself (GIY) start-up - California } \\
1 \text { organic box distributer - Ireland }\end{array}$ \\
& $\begin{array}{l}\text { Storage \& Preparation } \\
1 \text { online meal planning start-up - Northern Ireland } \\
1 \text { international kitchen device manufacturer - UK }\end{array}$ \\
& $\begin{array}{l}\text { Food Waste Recovery } \\
1 \text { national waste segregation start-up - Ireland } \\
1 \text { international composter manufacturer - Canada }\end{array}$ \\
\hline Public \& & $\begin{array}{l}\text { Government Advisor } \\
\text { NGO }\end{array}$ \\
& $\begin{array}{l}\text { Community Organisation } \\
1 \text { environmental enterprise - Ireland }\end{array}$ \\
& $\begin{array}{l}\text { Education / Awareness } \\
1 \text { heritage body - Ireland } \\
1 \text { food network - Ireland } \\
1 \text { government programme - Ireland }\end{array}$ \\
\hline
\end{tabular}


Table 2. Households recruited in the Eating HomeLabs.

\begin{tabular}{|c|c|c|c|c|c|}
\hline Profile & $\begin{array}{l}\text { Couple (C) } \\
\text { Household }\end{array}$ & $\begin{array}{l}\text { Family (F) } \\
\text { with young } \\
\text { (Y) children }\end{array}$ & $\begin{array}{l}\text { Mixed (M) } \\
\text { Non-familial } \\
\text { Household }\end{array}$ & $\begin{array}{l}\text { Single (S) } \\
\text { Person } \\
\text { Household }\end{array}$ & $\begin{array}{l}\text { Family (F) } \\
\text { with Adult } \\
\text { (A) children }\end{array}$ \\
\hline Identifier $^{1}$ & $\begin{array}{l}\text { Household } \\
\text { C }\end{array}$ & $\begin{array}{l}\text { Household } \\
\text { FY }\end{array}$ & $\begin{array}{l}\text { Household } \\
\text { M }\end{array}$ & Household S & $\begin{array}{l}\text { Household } \\
\text { FA }\end{array}$ \\
\hline Occupants & 2 & 4 & 3 & 1 & 4 \\
\hline $\begin{array}{l}\text { Pseudonym } \\
\text { \& Age }\end{array}$ & $\begin{array}{l}\text { Maeve } 27 \\
\text { Alan } 27\end{array}$ & $\begin{array}{l}\text { Ian } 40 \\
\text { Joanne } 34 \\
\text { Olly } 4 \\
\text { Lizzie } \\
\text { 18months }\end{array}$ & $\begin{array}{l}\text { Caroline } 32 \\
\text { Teresa } 29 \\
\text { Sinead } 28\end{array}$ & Marian 59 & $\begin{array}{l}\text { Paul } 63 \\
\text { Catherine } 61 \\
\text { Gráinne } 31 \\
\text { Eilíse } 28\end{array}$ \\
\hline Income $^{2}$ & Middle & Middle & Low & Low & High \\
\hline Home type & Apartment & $\begin{array}{l}\text { Semi- } \\
\text { detached }\end{array}$ & $\begin{array}{l}\text { Semi- } \\
\text { detached }\end{array}$ & $\begin{array}{l}\text { Semi- } \\
\text { detached }\end{array}$ & $\begin{array}{l}\text { Dormer } \\
\text { Bungalow }\end{array}$ \\
\hline Garden & No & Yes & Yes & Yes & Yes \\
\hline Location & Suburban $^{3}$ & Suburban & Suburban & Suburban & Rural $^{4}$ \\
\hline
\end{tabular}

\footnotetext{
${ }^{1}$ The Household keys outlined here (Household C, FY, M, S and FA) are used as identifiers in the results section along with the name of participants.

${ }_{2}^{2}$ Precise definitions of low, middle and high income are absent in Ireland (Collins, 2013), with probing income levels often considered overly intrusive. Income attributes are thus based on participants self-reported income ranking and any mention to budgetary constraints throughout the HomeLab study.

${ }^{3}$ In Ireland, suburbs are defined by the Central Statistics Office as "the continuation of a distinct population cluster outside its legally defined boundary in which no occupied dwelling is more than 200 metres distant from the nearest occupied dwelling" (CSO, 2002, p163)

${ }^{4}$ The CSO (2002, p164) defines aggregate rural areas as places where people reside "outside clusters of 1,500 or more inhabitants".
} 